renal cysts and renal cell carcinoma. Transplant Proc 1989: 21 : 1974.

18. Catalona WJ. Urothelial tumors of the urinary tract. In: Walsh PC, Retik AB. Stamey TA, Vaughn ER Jr. eds. Campbell's urology, 6th ed. Philadelphia: Saunders. 1992: 1094.

19. Bernstein J, Gardner KD Jr. Renal cvstir dicoses and mmni dysplasia. In: Walsh PC, Gittes RF,

TA, eds. Campbell's urology, 5th ed. 1986: 1760

20. Vaziri ND. Darwish R, Martin DC. Hc cystic disease in renal transplant rec 203.

21. Clinicopathologic conference: a new man with a transplanted kidney.

22. Almirall J, Ricart MJ, Campistol J $F$, Andreu J. Renal cell carcinom. disease after renal transplantatio
23. Faber M. Kupin W. Renal cell carcinoma and acquired cystic kidney disease after renal transplantation. Lancet $1987 ; 1$ : 1030.

24. Lien Y-HH. Kam I, Shanley PF, Schröter GPJ. Metastatic renal cell carcinoma associated with acquired cystic kidney disease successful renal transplantation. Am J Kidney 11.

akoon M, Wetzel LH. Small renal neoplasms: ogic and imaging findings. Am $\mathrm{J}$ Roentgenol

ek M. Improvement in survival of patients with 10ma: the role of the serendipitiously detected 988; 140: 487.

4.

4.
0041-1337/95/5904-485\$03.00/0 TRANSPLANTATION

Copyright $\odot 1995$ by Williams \& Wilkins
Vol. 59, 485-490, No. 4, February 27, 1995 Printed in U.S.A.

\title{
A PROSPECTIVE RANDOMIZED TRIAL OF FK506-BASED IMMUNOSUPPRESSION AFTER RENAL TRANSPLANTATION ${ }^{1}$
}

\author{
Ron Shapiro, ${ }^{2,3}$ Mark L. Jordan, ${ }^{2}$ Velma P. Scantlebury, ${ }^{2}$ Carlos Vivas, ${ }^{2}$ John J. Fung, ${ }^{2}$ \\ Jerry McCauley, ${ }^{2}$ Parmueet Randhawa, ${ }^{4}$ ANTHONy J. Demetris, ${ }^{4}$ William Irish, ${ }^{2}$ \\ Sandi Mitchell, ${ }^{2}$ Thomas R. Hakala, ${ }^{2}$ Richard L. Simmons, ${ }^{2}$ and Thomas E. Starzl ${ }^{2}$
}

Departments of Surgery and Pathology, Pittsburgh Transplantation Institute, University of Pittsburgh Medical Center, Pittsburgh, Pennsylvania 15213

A group of 204 adult patients was entered into a prospective, randomized trial comparing FK506/prednisone with FK506/azathioprine/prednisone after renal transplantation between August 1, 1991 and October 11,1992 . The purpose of the study was to see if the addition of azathioprine would reduce the incidence of rejection and improve graft survival. The recipient population was unselected, with $61(30 \%)$ patients undergoing retransplantation, $37(18 \%)$ having a panelreactive antibody greater than $40 \%$, and $33(16 \%)$ over 60 years of age. The mean recipient age was $43.8 \pm 13.7$ years (range 17.6-78). The mean donor age was $34.0 \pm 20.1$ years (range $0.3-75$ ); $13 \%$ of the cadaveric kidneys were from pediatric donors less than 3 years of age and were transplanted en bloc. The mean cold ischemia time was $31.4 \pm 8.4 \mathrm{hr}$. Living donors were the source of $13 \%$ of the kidneys. The mean follow-up was 22 \pm 4 months (range 12-29). Overall one-year actual patient survival was 94\%. Overall one-year actual graft survival was $87 \%$. Patients starting on double therapy had a one-year actual patient survival of $96 \%$ and a

Presented at the 13th Annual Meeting of the American Society of Transplant Physicians. May 16-18, 1994. Chicago, IL.

- Department of Surgery.

Address correspondence and reprint requests to Ron Shapiro. M.D.. 3601 Fifth Ave., 4th Floor Falk Clinic. Pittsburgh. PA 15213.

+ Department of Pathology. one-year actual graft survival of $92 \%$. Patients starting on triple therapy had a one-year actual patient survival of $91 \%$ ( $P=$ ns compared with double therapy), and a one-year actual graft survival of $82 \%(P<0.02$, compared with double therapy). Overall results with first cadaver transplants included a one-year actual patient survival of $94 \%$ and one-year actual graft survival of $88 \%$, with no differences between double and triple therapy. The overall incidence of rejection was $48 \%$, with $54 \%$ in the double therapy group and $41 \%$ in the triple therapy group $(P<.07)$. The incidence of steroid-resistant rejection requiring antilymphocyte therapy (OKT3 or ATGAM) was $13 \%$, and was not different between the double and triple therapy groups. The mean serum creatinine was $1.8 \pm 0.8 \mathrm{mg} / \mathrm{dl}$. The mean BUN was $33 \pm 21 \mathrm{mg} / \mathrm{dl}$, with no significant difference between the therapy groups. The mean serum cholesterol was $192 \pm 49 \mathrm{mg} / \mathrm{dl}$. A total of $56 \%$ of the patients are off prednisone, and $35 \%$ of the patients are not taking any antihypertensive medications. Other complications included cytomegalovirus-14\%; new-onset diabetes-16\% (half of which was reversible); and posttransplant lymphoproliferative disorder-1\%. There was a high incidence of crossover between the two groups, $27 \%$ of the patients in the double therapy group requiring the addition of azathioprine, and $45 \%$ of the patients in the triple therapy group requiring its discontinuation (usually tempo- 
rary). These results show that FK506 is an excellent immunosuppressive agent after renal transplantation and that azathioprine is not routinely effective as a third agent. A high quality of life resulted from the ability to use no $(56 \%)$ or low-dose maintenance steroids.

FK506 (Tacrolimus-Prograf) is a new immunosuppressive agent $(1-3)$ that has been recently approved by the Food and Drug Administration for use after liver transplantation (47). Promising clinical experiences with this drug have also been described in heart ( 8 ), lung (9), intestine (10), and islet (11) transplant patients. In renal transplantation, the initial studies, while encouraging, seemed to suggest that FK506 resulted in equivalent patient and graft survival when compared with cyclosporine-based regimens $(5,12-14)$. The differences were seen in secondary issues, such as an increased freedom from chronic steroids, a somewhat lower need for antihypertensive medications, and significantly lower serum cholesterol levels $(13,14)$. On the basis of these findings, a prospective randomized trial was begun in August 1991, comparing two FK506-based regimens-with and without azathioprine. The purpose was to see if the addition of azathioprine would help to improve the primary outcomes and patient and graft survival, and decrease the incidence of rejection. Early reports of this trial suggested that overall graft survival under FK506 was improving with experience, but that the benefit of azathioprine was unclear $(15,16)$. The data presented here reflect a minimum of one year of follow-up in the first 204 patients entered into this randomized trial, with actual survival calculations.

\section{MATERIALS AND METHODS}

Between August 1, 1991 and October 11, 1992, 204 patients were entered into a randomized trial comparing FK506/prednisone and FK506/azathioprine/prednisone. Inclusion and exclusion criteria, the details of randomization, and the immunosuppressive protocol have been previously described $(15,16)$. The patient population was unselected and represented virtually all of the adults undergoing renal transplantation alone at the University of Pittsburgh Medical Center during this period. There were a high percentage of retransplantations $(61[30 \%])$, sensitized recipients (PRA $>40 \%-37[18 \%])$, and older patients (age $>60-33[16 \%)$ ). There were $28(14 \%)$ black. 4 (2\%) Asian, and $2(1 \%)$ hispanic recipients. The mean recipient age was $43.8 \pm 13.7$ years (range $17.6-78$ ), and the mean donor age was $34.0 \pm 20.1$ years (range $0.3-75$ ). A total of $178(87 \%)$ transplantations were with cadaveric kidneys, and $26(13 \%)$ were with livingdonor kidneys. Of the cadaveric transplantations, $24(13 \%)$ were with pediatric en bloc kidneys from donors 3 years of age or younger. The mean cold ischemia time for the cadavenc cases was $31.4 \pm 8.4$ $\mathrm{hr}$. There were $7(3 \%) 6$-antigen-match and $13(6 \%) 0$-antigenmismatch cases.

There were more older patients $1>60$ years $)$ in the triple therapy group $(22 \%$ vs. $11 \%, P<.04)$ and more living-donor cases in the double therapy group $(18 \%$ vs. $8 \%, P<.04)$. The two groups were otherwise similar with regard to donor and recipient characteristics. The protocol was reviewed and approved by the Institutional Review Board of the University of Pittsburgh, and was renewed on a yearly basis.

Statistical Methods. The standard two-sample $t$ test was used to test differences in means while differences in proportions were tested using Pearson's chi-square test of association.

Patient survival was calculated from the date of kidney transplantation until death. and graft survival from the date of kidney transplantation until graft failure, retransplantation. or patient death.
Survival curves were generated using the Kaplan-Meier (productlimit) method and were compared using the generalized Wilcoxon (Breslow) test. A multivariate Cox's regression analysis was per. formed to adjust the relative risk of graft failure between the twn groups based on age of recipient (over 60 years) and living-donor cases. A stepwise procedure was performed to identify high-risk patients for graft failure using all available information collected. A $P$ value less than .05 was considered statistically significant. All analyses were performed according to intention-to-treat. unless otherwise stated.

\section{RESULTS}

The mean follow-up was $22 \pm 4$ months (range 12-29). The overall actual one-year patient survival was $94 \%$; in the double therapy group, it was $96 \%$, and in the triple therapy group, it was $91 \%$ (Fig. $1 ; P=0.10$ ).

The overall one-year actual graft survival was $87 \%$. In the double therapy group, it was $92 \%$, and in the triple therapy group, it was $82 \%$ (Fig. $2 ; P<0.02$ ). For first cadaver transplants, the one-year actual graft survival was $88 \%$; in the double therapy group, it was $90 \%$, and in the triple therapy group, it was $87 \%$ ( $P=$ ns). Comparative one-year actual graft survivals in specific subgroups are shown in Table 1. Triple therapy was associated with poorer one-year graft survival in cadaveric cases, in patients undergoing retransplantation, in patients with PRAs $>40 \%$, in patients with immediate graft function, in patients who experienced rejection, in recipients who did not receive pediatric en bloc kidneys, in nonblack recipients, and in cases where the donor or the recipient was less than 60 years of age. First transplants, living-donor cases, patients with PRAs $<40 \%$, patients receiving pediatric en bloc kidneys, patients experiencing ATN, patients not experiencing rejection, black recipients, and donors or recipients over 60 years of age showed no difference between double and triple therapy. With regard to specific subgroups. the only significant variable was the presence of ATN, which was associated with significantly worse one-year graft survival. In all of the other subgroups. no difference was seeni.e., outcome after retransplantation was similar to that seen with first transplants; patients with high PRAs did as well as with patients with low PRAs; blacks did as well as nonblacks:

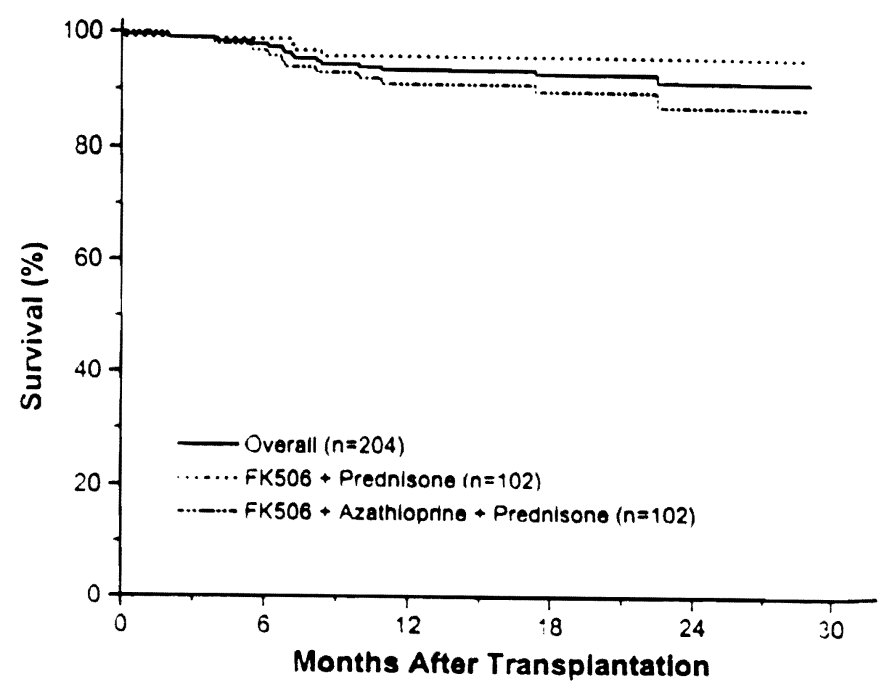

Figure 1. Patient survival. 


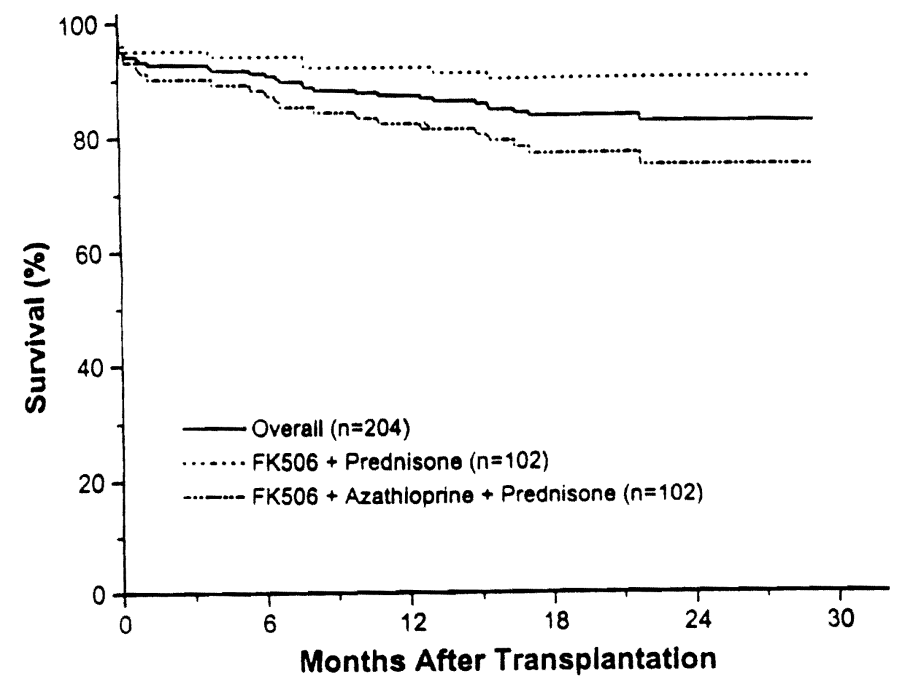

Figure 2. Graft survival.

TABLE 1. One year actual graft survival

\begin{tabular}{|c|c|c|c|c|c|}
\hline & 2-Drug & 3-Drug & Total & 2 vs. 3 & Subgroup \\
\hline Overall & $92 \%$ & $82 \%$ & $87 \%$ & $P<.02$ & \\
\hline 1st Cadaveric & $90 \%$ & $87 \%$ & $88 \%$ & NS & \\
\hline 1st Transplant & $90 \%$ & $87 \%$ & $89 \%$ & NS & NS \\
\hline Retransplantation & $97 \%$ & $72 \%$ & $84 \%$ & $P<.02$ & \\
\hline Cadaveric & $92 \%$ & $82 \%$ & $87 \%$ & $P<.03$ & NS \\
\hline Living-donor & $94 \%$ & $88 \%$ & $92 \%$ & NS & \\
\hline PRA $<40 \%$ & $91 \%$ & $84 \%$ & $87 \%$ & NS & NS \\
\hline PRA $>40 \%$ & $100 \%$ & $77 \%$ & $86 \%$ & $P<.04$ & \\
\hline Adult kidneys & $93 \%$ & $83 \%$ & $88 \%$ & $P<.02$ & NS \\
\hline En bloc & $80 \%$ & $79 \%$ & $79 \%$ & NS & \\
\hline No ATN & $100 \%$ & $88 \%$ & $93 \%$ & $P<.001$ & $P<.0001$ \\
\hline ATN & $81 \%$ & $71 \%$ & $77 \%$ & NS & \\
\hline Rejection & $91 \%$ & $76 \%$ & $85 \%$ & $P<.03$ & NS \\
\hline No rejection & $94 \%$ & $87 \%$ & $90 \%$ & NS & \\
\hline Donors $>60$ years & $77 \%$ & $80 \%$ & $78 \%$ & NS & NS \\
\hline Donors $<60$ years & $94 \%$ & $83 \%$ & $88 \%$ & $P<.02$ & \\
\hline Black & $92 \%$ & $87 \%$ & $89 \%$ & NS & NS \\
\hline Nonblack & $92 \%$ & $82 \%$ & $87 \%$ & $P<.02$ & \\
\hline Recipients $<60$ years & $93 \%$ & $83 \%$ & $88 \%$ & $P<.02$ & NS \\
\hline Recipients $>60$ years & $82 \%$ & $82 \%$ & $82 \%$ & NS & \\
\hline
\end{tabular}

patients who had rejection were not significantly different from patients who did not have rejection: and so on (Table 1 ).

A multivariate analysis was performed. using Cox's proportional hazards model. Two variables were associated with an increased likelihood of graft failure: the presence of ATN (relative risk 4.32 [95\% confidence interval 2.10-8.88], $P<.0001$ ), and initial immunosuppression with triple therapy (relative risk 2.83 (95\% contidence interval $1.35-5.93$ l, $P<.006$ ).
The mean serum creatinine, calculated creatinine clearance, and BUN were $1.8 \pm 0.8 \mathrm{mg} / \mathrm{dl}, 55 \pm 25 \mathrm{ml} / \mathrm{min}$, and $33 \pm 21 \mathrm{mg} / \mathrm{dl}$, and were not significantly different between double and triple therapy patients (Table 2).

The incidence of acute rejection was $48 \%$; in the double therapy group it was $54 \%$, and in the triple therapy group it was $41 \%$. This difference did not quite reach statistical significance $(P<.07)$. The incidence of rejection in specific subgroups is shown in Table 3 . In cadaveric cases, there was less rejection with triple therapy than with double therapy $(43 \%$ vs. $61 \%, P<.02$ ). In specific subgroups, retransplant patients had more rejection than recipients of first transplants; cadaveric cases had more rejection than living-donor cases; high-PRA patients had more rejection than low-PRA patients; black patients had more rejection than nonblacks; patients with ATN had more rejection than patients without ATN. Over $70 \%$ of the rejections were responsive to steroids and adjustment in the FK506 dosage. Antilymphocyte therapy was needed for steroid-resistant rejection in $13 \%$ of patients; there was no difference between double and triple therapy.

The incidence of initial nonfunction, defined as a lack of allograft urine output or a need for dialysis within the first week after transplantation, was $38 \%$; in the double therapy group it was $41 \%$, and in the triple therapy group it was $34 \%$ $(P=n s)$. The incidence of initial nonfunction in specific subgroups is shown in Table 4. Not surprisingly, cadaveric recipients had more ATN than living-donor recipients, and increasing cold ischemia time was associated with an increasing incidence of ATN. Blacks also had more ATN than nonblacks.

The incidence of cytomegalovirus disease or infection was 14\%; all were treated with gancyclovir. The CMV incidence for the 4 different donor/recipient serologic combinations is shown in Table 5 . The highest incidence, $38 \%$, was in the seropositive donor/seronegative recipient group $(P<.00001)$. All patients received high-dose acylovir prophylaxis; CMV hyperimmune globulin was also given to patients in the seropositive donor/seronegative recipient group.

The incidence of posttransplant lymphoproliferative disorder (PTLD) was 1\% ( 1 patient in each immunosuppressive group). In both cases, the PTLD disappeared with reduction of immunosuppression and initiation of gancyclovir therapy, and renal function was maintained. In addition, there was one case of Kaposi's sarcoma in a patient on triple therapy who was lost to follow-up after returning home outside the United States. It resolved after discontinuation of immunosuppression, but the patient eventually lost her allograft.

The incidence of new onset diabetes was $16 \%, 22 \%$ in the double therapy group, and $10 \%$ in the triple therapy group $(P<.04)$. Half these patients were able to be weaned off insulin once the FK506 and steroid dosages were reducedthus, the incidence of chronic new-onset insulin dependence was $8 \% ; 13 \%$ in the double therapy group and $4 \%$ in the triple therapy group $(P<.05)$.

TABLE 2. Renal function

\begin{tabular}{lccc}
\hline & 2-Drug & 3-Drug & Total \\
\hline Creatinine & $1.9 \pm 0.8$ & $1.8 \pm 0.8$ & $1.8 \pm 0.8 \mathrm{mg} / \mathrm{dl}$ \\
Creatinine clearance & $55 \pm 24$ & $56 \pm 26$ & $55 \pm 25 \mathrm{mg} / \mathrm{dl}$ \\
BUN & $33 \pm 22$ & $33 \pm 21$ & $3.3 \pm 21 \mathrm{mg} / \mathrm{dl}$ \\
\hline
\end{tabular}




\begin{tabular}{|c|c|c|c|c|c|}
\hline & 2-Drug & 3.Drug & Total & 2 vs. 3 & Subgroup \\
\hline Overall & $54 \%$ & $41 \%$ & $48 \%$ & NS & \\
\hline 1st Transplant & $49 \%$ & $36 \%$ & $43 \%$ & NS & $P<.04$ \\
\hline Retransplantation & $66 \%$ & $53 \%$ & $59 \%$ & NS & \\
\hline Cadaveric & $61 \%$ & $43 \%$ & $51 \%$ & $P<.02$ & $P<.007$ \\
\hline Living-donor & $22 \%$ & $25 \%$ & $23 \%$ & NS & \\
\hline $\mathrm{PRA}<40 \%$ & $49 \%$ & $35 \%$ & $43 \%$ & NS & $P<.002$ \\
\hline $\mathrm{PRA}>40 \%$ & $80 \%$ & $64 \%$ & $70 \%$ & NS & \\
\hline No ATN & $43 \%$ & $34 \%$ & $39 \%$ & NS & $P<.001$ \\
\hline ATN & $69 \%$ & $54 \%$ & $62 \%$ & NS & \\
\hline Black & $85 \%$ & $67 \%$ & $75 \%$ & NS & $P<.002$ \\
\hline Nonblack & $49 \%$ & $37 \%$ & $43 \%$ & NS & \\
\hline Donors $>60$ years & $62 \%$ & $50 \%$ & $57 \%$ & NS & NS \\
\hline Donors $<60$ years & $53 \%$ & $40 \%$ & $46 \%$ & NS & \\
\hline Recipients $<60$ years & $55 \%$ & $45 \%$ & $50 \%$ & NS & NS \\
\hline Recipients $>60$ years & $46 \%$ & $27 \%$ & $33 \%$ & NS & \\
\hline
\end{tabular}

TABLE 4. ATN

\begin{tabular}{|c|c|c|c|c|c|}
\hline & 2-Drug & 3-Drug & Total & 2 vs. 3 & Subgroup \\
\hline Overall & $41 \%$ & $34 \%$ & $38 \%$ & NS & \\
\hline 1st Transplant & $37 \%$ & $31 \%$ & $34 \%$ & NS & NS \\
\hline Retransplantation & $52 \%$ & $41 \%$ & $46 \%$ & NS & \\
\hline Cadaveric & $48 \%$ & $37 \%$ & $42 \%$ & NS & $P<.001$ \\
\hline Living-donor & $11 \%$ & 0 & $8 \%$ & NS & \\
\hline PRA $<40 \%$ & $40 \%$ & $29 \%$ & $35 \%$ & NS & NS \\
\hline $\mathrm{PRA}>40 \%$ & $47 \%$ & $55 \%$ & $51 \%$ & NS & \\
\hline Black & $54 \%$ & $60 \%$ & $57 \%$ & NS & $P<.03$ \\
\hline Nonblack & $39 \%$ & $30 \%$ & $35 \%$ & NS & \\
\hline Donors $>60$ years & $54 \%$ & $50 \%$ & $52 \%$ & NS & NS \\
\hline Donors $<60$ years & $39 \%$ & $33 \%$ & $36 \%$ & NS & \\
\hline Recipients $<60$ years & $42 \%$ & $31 \%$ & $37 \%$ & NS & NS \\
\hline Recipients $>60$ years & $36 \%$ & $46 \%$ & $42 \%$ & NS & \\
\hline \multicolumn{6}{|l|}{ CIT } \\
\hline$\therefore 12 \mathrm{hr}$ & $11 \%$ & 0 & $8 \%$ & NS & $P<.0001$ \\
\hline $24 \mathrm{hr}$ & 0 & $29 \%$ & $16 \%$ & NS & \\
\hline$\therefore 24 \mathrm{hr}$ & $46 \%$ & $30 \%$ & $39 \%$ & NS & \\
\hline $36 \mathrm{hr}$ & $79 \%$ & $53 \%$ & $63 \%$ & NS & \\
\hline
\end{tabular}

Crossover was seen frequently. In the double therapy group. $27 \%$ of patients received azathioprine at one time or another. and virtually all of these patients were permanently switched to triple therapy. In the triple therapy group. $45 \%$ of patients were taken off azathioprine at one time or another, and $11 \%$ remain off azathioprine permanently. The main reason for conversion from double to triple therapy was rejection. and the main reason for conversion from triple to double therapy was neutropenia or liver dysfunction. The
TABLE 5. CMV

\begin{tabular}{rrrrrr}
\hline & 2-Drug & 3-Drug & Total & 2 vs. 3 & Subgroup \\
\hline Overall & $12 \%$ & $15 \%$ & $14 \%$ & NS & \\
$+\rightarrow-$ & $30 \%$ & $47 \%$ & $38 \%$ & NS & \\
$+\rightarrow+$ & $3 \%$ & $8 \%$ & $6 \%$ & NS & $P<.00001$ \\
$-\rightarrow-$ & $11 \%$ & $15 \%$ & $13 \%$ & NS & \\
$-\rightarrow+$ & $10 \%$ & $7 \%$ & $8 \%$ & NS & \\
\hline
\end{tabular}

one-year actual patient and graft survivals in patients currently on double therapy were $94 \%$ and $86 \%$; in patients currently on triple therapy, they were $93 \%$ and $88 \%(P=n s)$.

The mean FK506 dosage was $10.3 \pm 5.8 \mathrm{mg} /$ day $(0.15 \pm 0.10$ $\mathrm{mg} / \mathrm{kg} /$ day) and was not different between the 2 treatment groups. The mean FK506 level was $0.88 \pm 0.72 \mathrm{ng} / \mathrm{ml}$ and was also not different between the 2 groups.

A total of $56 \%$ of the patients have been weaned off steroids. $57 \%$ in the double therapy group and $56 \%$ in the triple therapy group; $5 \%$ had steroids withdrawn and then restarted because of rejection-none of these patients lost their allograft. The mean prednisone dose was $3.7 \pm 5.6 \mathrm{mg} / \mathrm{day}$; in patients still on steroids, it was $7.8 \pm 5.7 \mathrm{mg} /$ day.

A total of $35 \%$ of the patients were off antihypertensive medications-30\% in the double therapy group and $40 \%$ in the triple therapy group. The mean number of antihypertensive medications required was $1.0 \pm 1.0,1.1 \pm 1.0$ in the double therapy group and $0.9 \pm 1.0$ in the triple therapy group.

The mean serum cholesterol was $192 \pm 49 \mathrm{mg} / \mathrm{dl}$, and was not different between the two groups.

\section{DISCUSSION}

Current expectations in renal transplantation are high: there is a presumption that no more than $5-10 \%$ of patients will die within the first year after transplantation, and that no more than $15-25 \%$ of patients will lose their allogratt within the first year (17). While these results are not perfect. they are considerably better than they were 15 years ago (18), and represent maturation of a field that barely existed 35 years ago. However, current outcomes offer little reason for complacency, and active investigation of new immunosuppressive agents is proceeding around the world. FK506, the farthest along of these agents, has already been demonstrated to be a superior drug for liver transplantation (4-6. 7). Experience with kidney transplantation, including the data reported here, has suggested improving outcomes with FK506, in unselected patients, that equal or surpass the best results obtainable with conventional therapy $(15,16)$. Of perhaps greater significance is the ability to withdraw steroids in more than half the patients. Other trials, from Japan and the United States, have demonstrated excellent outcomes $(19-21)$. If comparable results are seen with the ongoing American and European multicenter trials, this will confirm the utility of FK506 as a formidable addition to the immunosuppressive armamentarium in renal transplantation.

The goal of the current randomized trial was to assess the ability of preemptive azathioprine to reduce the incidence of rejection and safely improve graft survival beyond that achievable with FK506 and prednisone alone. While the addition of azathioprine was associated with less rejection. 
particularly in cadaveric recipients. the reduction was not significant-and in fact, overall graft survival was worse in patients starting on triple therapy. There was a high incidence of crossover in both treatment limbs, but nearly twice as many from triple to double as from double to triple therapy. Thus the routine administration of azathioprine as a third agent was not advantageous. Nevertheless, about one quarter of the patients who self-selected to delayed azathioprine were thought to have derived benefit from it.

The apparent superiority of FK506 and prednisone alone and the outstanding results in patients with a higher-thanaverage risk profile raises questions about the wisdom of polypharmaceutical immunosuppression as complex as in the ongoing American multicenter randomized trial comparing cyclosporine and FK-506 for renal transplantation. In these trials, a sequential four-drug regimen is being used, beginning with induction antilymphocyte therapy and azathioprine. If azathioprine is confirmed to be without value in these trials, it may be that one of the new agents on the horizon such as mycophenolate mofetil (RS-61443) (22), brequinar (23), rapamycin (24), leflunomide (25), or deoxyspergualin (26) will be an effective third agent. It is noteworthy that even with cyclosporine convincing controlled studies showing the value of triple or quadruple therapy versus cyclosporine-prednisone are not available (27-29).

The side effects of FK506 are similar to those seen with cyclosporine, the principal ones being nephrotoxicity $(30-34)$, neurotoxicity (35), and diabetogenicity (36). These are all dose-related and largely reversible with dose reduction. The infectious profile is also similar to that observed in past experience (14), although in liver recipients, the mortality from infectious complications has been significantly less (7). Hirsutism and gingival hyperplasia do not occur with FK506 $(12-14)$. The long-term liability of hypercholesterolemia and refractory arterial hypertension have been reduced in recipients of various organs-a particular advantage for pediatric renal $(37,38)$ and heart recipients $(39)$. One-third of the adults in the present series require no antihypertensive medications.

Our global assessment is that FK506 is a highly effective agent for renal transplant patients, once its nuances have been mastered. The addition of azathioprine to the combination of FK506 and prednisone was not uniformly advantageous, although there are some patients who may have benefited from the secondary use of azathioprine for specific indications. Further improvements in the short-term-and particularly the long-term-outlook after renal transplantation may depend more on biologic immune modulation, as with the adjuvant administration of donor bone marrow that has been reported elsewhere (40).

Acknowledgments. We would like to thank Regina Fenton. RN. BSN, CCTC, Loraine Kaminski, RN, Deborah Good. RN, BSN, CCTC, Holly Woods, RN. CCTC, Jareen Flohr, RN, BSN, Sue Bauder, RN, Janice Zagari. RN, BSN, Jennifer Ovesney, RN, BSN, and Sharon Orlofske. RN, for their help with patient care: Janet Schmelzer for her help with data entry and organization; David Krakosky for his help with graph and slide preparation: Kate Carr for her help with slide preparation: and Karen Toler for her help with typing the manuscnpt and table and slide preparation.

\section{REFERENCES}

1. First International Workshop on FK506: A Potential Breakthrough in Immunosuppression, October, 1987, Gothenburg, Sweden. Transplant Proc 1987; 19 (suppl 6): 3.

2. Second International Workshop on FK506: A Potential Breakthrough in Immunosuppression-Clinical Implications. February 1990, Barcelona, Spain. Transplant Proc 1990; 22 (suppl 1): 5.

3. Proceedings of the First International Congress on FK506, December, Pittsburgh. Transplant Proc 1991; 23: 2709.

4. Fung JJ, Abu-Elmagd $K$. Jain A, et al. A randomized trial of primary liver transplantation under immunosuppression with FK506 vs. cyclosporine. Transplant Proc 1991; 23: 2977.

5. Todo S, Fung JJ, Starzl TE. Liver, kidney, and thoracic organ transplantation under FK506. Ann Surg 1990; 212: 295.

6. Klintmalm G. The U.S. Multi-center FK506 Liver Study Group. A comparison of tacrolimus (FK506) and cyclosporine for immunosuppression after liver transplantation. N Engl J Med 1994; 331: 1110.

7. Todo S, Fung JJ, Starzl TE, et al. Single-center experience with primary orthotopic liver transplantation under FK506 immunosuppression. Ann Surg (in press).

8. Armitage JM. Kornos RL. Fung JJ, Starzl TE. The clinical trial of FK506 as a primary and rescue immunosuppression in adult cadaveric transplantation. Transplant Proc 1991; 23: 3054.

9. Griffith BP, Bando K, Hardesty RL, et al. A prospective randomized trial of FK506 versus cyclosporine after human pulmonary transplantation. Transplantation 1994; 57: 848.

10. Todo S, Tzakis A, Reyes J, et al. Small intestinal transplantation in humans with or without the colon. Transplantation 1994; 57: 840 .

11. Ricordi C, Tzakis A, Carroll P, et al. Human islet allotransplantation under FK506. Transplant Proc 1991; 23: 3207.

12. Starzl TE, Fung JJ, Jordan M. et al. Kidney transplantation under FK506. JAMA 1990; 264: 63.

13. Shapiro R, Todo S, Starzl TE. Kidney transplantation under FK506 immunosuppression. Transplant Proc 1991; 23: 920.

14. Shapiro R, Jordan ML, Scantlebury V, et al. FK506 in clinical kidney transplantation. Transplant Proc 1991: 23: 3065.

15. Shapiro R. Jordan M. Scantlebury V, et al. Randomized trial of FK506/prednisone vs. FK506/azathioprine/prednisone after renal transplantation: preliminary report. Transplantation Proc 1993; $25: 669$.

16. Shapiro R, Jordan M, Scantlebury V, et al. A prospective, randomized trial of FK506 in renal transplantation-a comparison between double and triple drug therapy. Clin Transplant 1994: 8: 508.

17. Cecka JM. Terasaki PI. In: Terasaki PI. Cecka JM, eds, Clinical transplants 1992. Los Angeles: UCLA Tissue Typing Laboratory, 1993: 1 .

18. Teresaki PI, Toyotome A. Mickey MR, et al. In: Terasaki PI, ed. Clinical kidney transplant 1985. Los Angeles: UCLA Tissue Typing Laboratory, 1985: 1.

19. Japanese FK506 Study Group. Japanese study of FK506 on kidney transplantation: the benefit of monitoring the whole blood FK506 concentration. Transplant Proc 1991; 23: 3085.

20. Japanese FK506 Study Group. Japanese study of FK506 on kidney transplantation: results of late phase II study. Transplant Proc 1993; 25: 649.

21. Neylan J, Whelchel J, Laskow D. et al. Adverse events in the comparative dose finding trial of FK506 in primary renal transplantation. Presented at the 13th Annual Meeting of the American Society of Transplant Physicians. May 16-18. 1993, Chicago, IL.

22. Sollinger HW. Deierhoi MH. Belzer FO, Diethelm AG, Kauffman RS: RS-61443-A phase I clinical trial and pilot rescue study. Transplantation 1992: 53: 428. 
23. Makowka L. Chapman F. Cramer DV. Historical development of brequinar sodium as a new immunosuppressive drug for transplantation. Transplant Proc 1993; 25: 2.

24. Morris RE. Rapamycin: FK506's fraternal twin or distant cousin? Immunol Today 1991: 12: 137.

25. Chong AS-F, Gebel H, Finnegan A, et al. Leflunomide, a novel immunomodulatory agent: in vitro analyses of the mechanism of immunosuppression. Transplant Proc 1993; 25: 1: 747.

26. Morris RE. \pm 15 -deoxyspergualin: A mystery wrapped within an enigma. Clin Transplant 1991; 5: 530.

27. Brinker KR. Dickerman RM. Gonwa TA, et al. A randomized trial comparing double-drug and triple-drug therapy in primary cadaveric renal transplants. Transplantation 1990; 50: 43.

28. Lindholm A, Albrechtsen D, Tufveson G, Karlberg I, Persson NH, Groth CG. A randomized trial of cyclosporine and prednisone versus cyclosporine, azathioprine, and prednisolone in primary cadaveric renal transplantation. Transplantation 1992; 54: 624.

29. Cecka JM, Young WC, Teresaki PI. Analyses of the UNOS scientific renal transplant registry at three years-early events affecting transplant success. Transplantation 1992; 53: 1: 59.

30. McCauley J, Takaya S, Fung J, Tzakis A, Abu-Elmagd K, Jain A, Todo S, Starzl TE. The question of FK506 nephrotoxicity after liver transplantation. Transplant Proc 1991: 23: 1444.

31. Starzl TE, Abu-Elmagd K, Tzakis A, Fung JJ, Porter KA, Todo S. Selected topics on FK506, with special references to rescue of extrahepatic whole organ grafts, transplantation of "forbidden organs," side effects, mechanisms, and practical pharmacokinetics. Transplant Proc 1991; 23: 914.

32. Starzl TE: FK506 versus cyclosporine. Transplant Proc 1993; 25 511.
33. Demetris AJ, Banner B. Fung JJ, Shapiro R, Jordan M. Starzl M. Histopathology of human renal allograft function under FK506: a comparison with cyclosporine. Transplant Proc 1991; 23: 944.

34. Randhawa PS. Shapiro R. Jordan ML. Starzl TE, Demetris AJ. The histopathological changes associated with allograft rejection and drug toxicity in renal transplant recipients maintained on FK506: clinical significance and comparison with cyclosporine. Am J Surg Pathol 1993; 17: 60.

35. Shapiro R, Fung JJ, Jain AB, Parks P, Todo S, Starzl TE. The side effects of FK506 in humans. Transplantation Proc 1990; 22(suppl 1): 35 .

36. Scantlebury V, Shapiro R. Fung JJ, et al. New onset of diabetes in FK506 vs. cyclosporine-treated kidney transplant recipients. Transplant Proc 1991; 23: 3169.

37. Ellis D, Shapiro R, Jordan ML, et al. Comparison of FK506 and cyclosporine regimens in pediatric renal transplantation. Pediatr Nephrol 1994; 8: 193.

38. Shapiro R, Scantlebury V, Jordan ML, et al. FK506 in pediatric kidney transplantation-primary and rescue experience. Kidney Int (in press).

39. Armitage JM, Fricker FJ, Del Nido P, Cipriani L, Starzl TE. The clinical trial of FK506 as primary and rescue immunosuppression in pediatric cardiac transplantation. Transplantation Proc 1991; 23: 3058.

40. Fontes P, Rao AS, Demetris AJ, et al. Augmentation with bone marrow of donor leukocyte migration for kidney, liver, heart, and pancreas islet transplantation. Lancet $1994 ; 344: 151$.

Received 26 May 1994.

Accepted 16 August 1994.
$0041-1337 / 95 / 5904-490 \$ 03.00 / 0$

TRANSPLANTATION

Copynght $(1) 1995$ by Williams \& Wilkins
Vol. 59, 490-494, No, 4, February 27, 1995 Printed in U.S.A

\title{
THROMBOXANE SYNTHASE EXPRESSION IN RENAL TRANSPLANT PATIENTS WITH REJECTION ${ }^{1}$
}

\author{
Eleanor L. Ramos, ${ }^{2.3}$ Yousri M. Barri, ${ }^{4,5}$ Byron P. Croker ${ }^{6}$ William L. Clapp ${ }^{6}$ \\ John C. Peterson, ${ }^{4}$ AND Christopher S. Wilcox ${ }^{4,7}$
}

Division of Nephrology, Department of Medicine, and Department of Pathology, University of Florida. Gainesuille, Florida 32610-0224

Thromboxane synthase (TS) catalyzes the formation of thromboxane $\left({\left.\mathrm{T} x \mathrm{~A}_{2}\right)}\right.$ in monocytes/macrophages,

' Presented at the 13th Annual Meeting of the American Society of Transplant Physicians, May 16-18. 1994. Chicago, IL.

"Supported in part by Division of Sponsored Research. University of Florida.

${ }^{3}$ Address correspondence to: Eleanor L. Ramos, M.D., Division of Nephrology, University of Florida, PO Box 100224, Gainesville, FL 32610-0224.

Division of Nephrology, Department of Medicine, University of Florida.

${ }^{3}$ Current address: Department of Medicine, Presbyterian Hospital of Dallas. 8200 Walnut Hill Lane, Dallas. TX 75231. platelets, and various tissues. $T \times \mathrm{A}_{2}$ is likely to play a role in graft dysfunction due to its vasoconstrictive and platelet aggregatory properties.

We studied the expression of TS in 7 normal native kidneys, 29 consecutive renal allograft biopsies (performed for rising serum creatinine, $n=23$, and delayed graft function, $n=6$ ), and one transplant nephrectomy specimen with severe acute rejection. TS expression was determined by immunocytochemistry using a

\footnotetext{
Department of Pathology, University of Florida.

- Current address: Chief, Division of Nephrology and Hvpertension. Department of Medicine Georgetown University Medical Center, 3800 Reservoir Rd, NW-5 PHC, Washington. DC 20007.
} 